\title{
Agôn
}

Revue des arts de la scène

Critiques | Saison 2010-2011

\section{Devant la folle réalité, la belle urgence de l'art}

Les Naufragés du Fol Espoir (Aurores)

\section{Quentin Rioual}

\section{(2) OpenEdition \\ Journals}

\section{Édition électronique}

URL : http://journals.openedition.org/agon/1635

DOI : 10.4000/agon.1635

ISSN : 1961-8581

Éditeur

Association Agôn

\section{Référence électronique}

Quentin Rioual, « Devant la folle réalité, la belle urgence de l'art », Agôn [En ligne], Critiques, mis en ligne le 12 février 2011, consulté le 23 septembre 2020. URL : http://journals.openedition.org/agon/1635 ;

DOI : https://doi.org/10.4000/agon.1635

Ce document a été généré automatiquement le 23 septembre 2020.

Association Agôn et les auteurs des articles 


\title{
Devant la folle réalité, la belle urgence de l'art
}

\author{
Les Naufragés du Fol Espoir (Aurores)
}

Quentin Rioual

\section{RÉFÉRENCE}

Les Naufragés du fol espoir (Aurores). Création collective du Théâtre du Soleil, Mise en scène : Ariane Mnouchkine. Pièce librement adaptée d'un roman de Jules Verne, miécrite par Hélène Cixous, créée à la Cartoucherie, Théâtre du Soleil le 10 février 2010.

1 "Avez-vous pris le numéro de votre place?» me demande-t-on alors que je présente un billet, comme à l'accoutumée, m'ayant tout l'air d'être valable... «Car il faut prendre le numéro de votre place", une place à bord; nous ne sommes pas seulement dans un théâtre mais aussi dans le vaisseau démesuré du Fol Espoir. Tout y crée le voyage et l'événement: de la présence en province de la troupe du Théâtre du Soleil à ce palais des Sports de Lyon à la voûte maculée de projecteurs comme des étoiles, jusqu'à ces loges-cabines aux voiles transparents au travers desquels : les comédiens. Après avoir pris place, accueilli par d'élégants hommes comme on n'en voit plus et dont on regretterait presque la moustache bien enlevée, je me trouve face à un voile opaque blanc qui dérobe la scène aux regards et les détournent alors : dans les loges, les comédiens donnent le dernier coup de crayon, puis peu à peu, les lampes au beige passé s'éteignent. Deux coups de tête : toutes ont été éteintes sauf trois, voiles noirs sur les voiles transparents. 
Les Naufragés du fol espoir, par le Théâtre du Soleil, mise en scène Ariane Mnouchkine

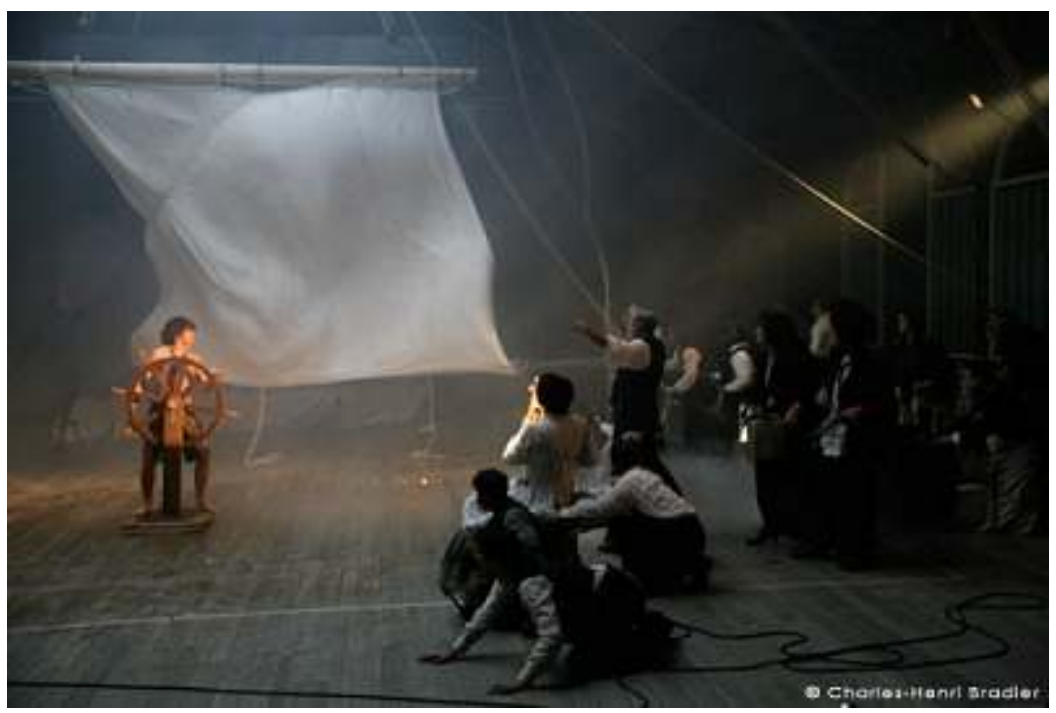

(C) DR

2 C'est l'aventure, le plaisir enfantin du départ, l'effervescence de la préparation, du contretemps technique. Ariane Mnouchkine veille au départ du navire, debout sur le côté des gradins, un peu en retrait. Le voile blanc opaque est descendu : l'écran de cinéma se retire pour la scène profonde du théâtre, plongée dans le noir... Mais les personnages de cette pièce ne quitteront jamais le cinéma: Jean Lapalette, cinéaste remercié par les studios Pathé en raison de ses engagements socialistes, veut participer à ce qu'il considère comme l'avenir d'un peuple et d'un art: le cinéma d'éducation populaire. Il engage alors toute une équipe de proches, à commencer par Gabrielle, sa sœur, pour filmer une adaptation d'un roman de Jules Verne. Mais le cinéma s'apprivoise difficilement, et le temps n'aide pas : la Belle Epoque se termine, 1914 en sonne le glas bientôt destructeur.

3 S'entrecroisent, pendant quatre heures, cette fable ainsi que celle du film tourné : un navire à destination de l'Australie, Le Fol Espoir, s'échoue au Cap Horn après une tempête ravageuse. Cette mise en intrigue complexe fait osciller l'hyperactivité de l'équipe de tournage avec les jeux burlesques d'acteurs n'écoutant pas les consignes d'un cinéaste parfois autoritaire. De la plus belle des manières, le jeu d'exacerbation des gestes et des signes propre aux films muets crée, au présent de la scène théâtrale, un effet comique irrésistible. Le dispositif technique exceptionnel, dans lequel chaque comédien occupe sa place, et les immenses toiles peintes de Danièle Heusslein-Gire conjuguent magiquement l'art théâtral et l'art cinématographique qui renaît sous nos yeux. Peu à peu, c'est toute la scène qui sert de plateau de tournage, non plus seulement une surface réduite de celle-ci. Tout est contaminé. Qui l'eût cru, l'exhibition de la théâtralité participe ici à la construction du réalisme cher au cinéma mais selon des mailles croisées : au décor et aux costumes le mimético-naturalisme, au tournage l'artificialité ! 
Les Naufragés du fol espoir, par le Théâtre du Soleil, mise en scène Ariane Mnouchkine

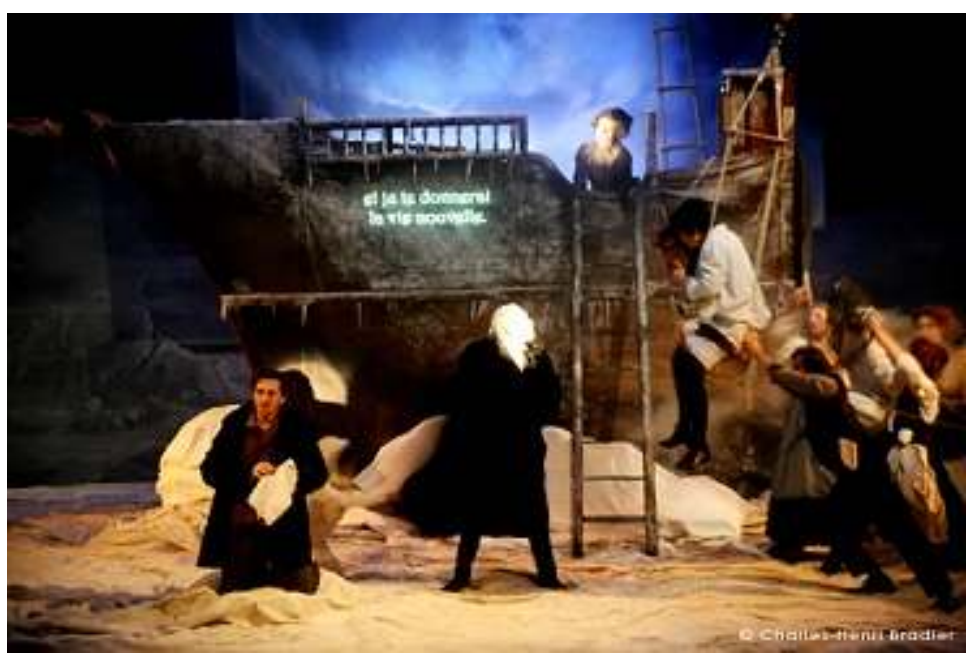

(c) DR

4 Cette belle et (un peu trop) longue entreprise pèche toutefois en quelques endroits. Le rythme du tournage, de moins en moins interrompu, s'essouffle par moments. Le mutisme pèse d'autant plus que le texte d'Hélène Cixous est étonnamment pauvre et difficilement sauvé par la voix narrative en off. On regrette aussi la prestation grandiloquente de Maurice Durozier, premier rôle, dont les adresses peu précises mettent au ban la justesse de nombreuses répliques.

5 Mais peut-être est-ce peu devant la belle urgence de cette troupe composée d'une trentaine de comédiens et d'une équipe artistique au nombre incroyable, procurant un peu du rêve théâtral perdu. Alors que survient dans la fable du film, la mort de Pierre Ceyrac, géographe utopiste rêvant d'instaurer un régime démocratique socialiste sur cette terre gelée du Cap Horn, la mort de Jean Jaurès, dans la fable de la pièce, vient éloigner le fol espoir de quelque repos, de quelque insouciance, de quelque rêve réalisé. Tous les acteurs sont reconduits vers le tournage, vers l'urgence de l'art, seul capable encore d'alimenter l'espérance et de construire le progrès, de "concrétiser cet espoir d'une épopée humaine qui ne serait pas sanglante, qui ne serait pas dictatoriale... Ni fasciste, ni stalinienne ${ }^{1}$, selon les mots d'Ariane Mnouchkine. Car si la réalité et la politique ont souvent été décevantes, l'art et sa fabrique pourront encore parfois ne pas l'être.

En tournée au Palais des Sports - Théâtre des Célestins à Lyon du 29 janvier au 20 février.

\section{NOTES}

1. Propos rapportés d'un entretien avec Ariane Mnouchkine organisé par le théâtre des Célestins, diffusé le 31 mai 2010. Entretien disponible sur: http://www.youtube.com/watch? $\mathrm{v}=\mathrm{nVmevrMovds}$ 
INDEX

Mots-clés : Les Naufragés du fol espoir, Théâtre du Soleil, Mnouchkine (Ariane), La Cartoucherie 